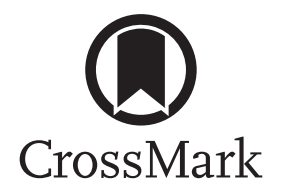

\title{
Interaction effect of psychological distress and asthma control on productivity loss?
}

\author{
Grégory Moullec ${ }^{1}$, J. Mark FitzGerald ${ }^{1,2}$, Roxanne Rousseau ${ }^{1,2}$, Wenjia Chen ${ }^{1,3}$, \\ Mohsen Sadatsafavi ${ }^{1,2,3}$ and the Economic Burden of Asthma (EBA) study team ${ }^{4}$
}

Affiliations: ${ }^{1}$ Centre for Clinical Epidemiology and Evaluation, Vancouver Coastal Health Research Institute, University of British Columbia, Vancouver, BC, Canada. ${ }^{2}$ Institute for Heart and Lung Health, Department of Medicine, University of British Columbia, Vancouver, BC, Canada. ${ }^{3}$ Collaboration for Outcomes Research and Evaluation, Faculty of Pharmaceutical Sciences, University of British Columbia, Vancouver, BC, Canada. ${ }^{4}$ For details of the EBA study team, please see the Acknowledgements section.

Correspondence: Grégory Moullec, Centre for Clinical Epidemiology and Evaluation, 7th Floor, 828 West 10th Avenue, Research Pavilion, Vancouver, BC V5Z 1M9, Canada. E-mail: greg.moulleclagmail.com

ABSTRACT Little is known about the potential synergistic effect of comorbid psychological distress (PD) and uncontrolled asthma (UA) on productivity loss. We estimated the productivity loss associated with the combination of these two potentially preventable conditions in employed adults with asthma.

A population-based random sample of 300 adults with asthma in British Columbia, Canada, was prospectively recruited between Dec 2010 and Aug 2012. PD and productivity loss due to absenteeism and presenteeism was measured using validated instruments, and asthma control was ascertained using 2010 Global Initiative for Asthma management strategy. We used two-part regression models to study the contribution of UA and PD to productivity loss.

Compared with reference group (controlled asthma (CA)+noPD), those with UA+noPD had CAD\$286 (95\%CI \$276-297) weekly productivity loss, and those with CA+PD had CAD\$465 (\$445-485). Those with UA+PD had CAD $\$ 449$ (437-462) in productivity loss. There was no significant interaction effect of PD with asthma control levels on productivity loss ( $\mathrm{p}=0.22)$.

In patients without $\mathrm{PD}$, uncontrolled asthma was associated with a higher productivity loss than controlled asthma, but this was not the case in patients with PD. This finding can be explained by the fact that the contribution of PD to productivity loss is so large that there is no room for synergy with asthma control. Future studies should assess the impact of interventions that modify PD in patients with asthma.

@ERSpublications

With psychological distress, the further additive effect of asthma control on productivity loss is minimal http://ow.ly/GYIVG

This article has supplementary material available from erj.ersjournals.com

Received: Aug 012014 | Accepted after revision: Dec 072014 | First published online: Feb 052015

Support statement: This study is funded through the Collaborative Innovative Research Fund (CIRF), an investigator-initiated, peer-reviewed competition sponsored by GlaxoSmithKline Canada. GSK played no role in the study design, data analysis, interpretation or publication of the results.

Conflict of interest: Disclosures can be found online alongside the online version of this article at erj.ersjournals.com

Copyright @ERS 2015 


\section{Introduction}

Several studies have documented a disappointingly high prevalence of poorly controlled asthma [1-3]. Poorly controlled asthma places an excess burden in terms of direct healthcare costs as it is associated with increased rates of asthma-related hospitalisations [4,5] we well as emergency department visits $[4,5]$, and use of medications [6,7]. However, the increased consumption of medical resources is not the only factor associated with uncontrolled asthma [8-11]. Patients with asthma also experience productivity loss. They often miss work during asthma exacerbations (absenteeism). Even when attending workplace, the impairment due to symptoms can cause loss of functionality (presenteeism) [12, 13]. Given that asthma affects individuals across all age groups, including those in the prime working years of their lives, and given the disappointingly high prevalence of uncontrolled asthma [1-3], the burden of productivity loss attributable to uncontrolled asthma is likely significant. A number of studies have estimated that loss of productivity costs are larger than direct costs in asthma $[8,14]$.

Asthma is also associated with an increased risk of psychological distress (PD) [15], which is a known cause of both increased healthcare resource use [16] and productivity loss [17]. A few studies have examined the impact of comorbid PD and asthma on work productivity [18-20]. They reported an additive effect on productivity loss (due to both presenteeism and absenteeism), accounting for a substantial economic burden in individuals that suffer from both conditions. However, the current conventional wisdom is that asthma cannot be cured, and there are limited evidence-based options to prevent its development. The emphasis of asthma management is therefore focussed on achieving current symptom control and the prevention of future risk [21]. From this perspective, it is much more relevant to evaluate the interaction of asthma control and PD in determining the burden of asthma, as the resulting estimate can be interpreted as "preventable" burden: the reduction in burden that can be achieved by treating PD and achieving asthma control.

Therefore, this population-based study aimed to narrow this evidence gap by quantifying productivity loss, in terms of presenteeism and absenteeism, as a function of level of asthma control and presence of PD, in employed adults with asthma. Moreover, we assessed whether the potential interaction effect between asthma control and PD within sub-types of PD (clinical levels of depressive symptomatology alone, anxiety symptomatology alone, or combination of both).

\section{Methods}

Study design

This study was conducted as part of a larger 1-year longitudinal study (the Economic Burden of Asthma (EBA) study) designed to estimate the direct and indirect costs of asthma and the impact of asthma on quality of life (University of British Columbia Human Ethics \#H10-01542). We used the prospectively collected cross-sectional data from the baseline visit for the current study. The study has been described in detail elsewhere $[13,22]$.

\section{Setting and participants}

The study's catchment areas were comprised of two census subdivisions covering urban and rural populations: Vancouver and Central Okanagan, with a 2006 population of 578014 and 162276, respectively [23]. For the original EBA study, individuals aged 1-85 years old with a self-reported diagnosis of asthma by a physician were identified using random digit dialling (including both landline and mobile telephone numbers). We specifically targeted both landline and mobile telephone to ensure high coverage of the target population. For the present study, we restricted the sample to adults (19 years and older). Other eligibility criteria were similar to that of the EBA study and included having had at least one encounter with the healthcare system due to asthma (e.g., visit to a doctor, emergency department or hospital, or receiving an inhaler medication) in the past five years and having no plans to move out of the study region in the next year. The response rate was $75 \%$.

\section{Procedure}

Between December 2010 and August 2012, eligible individuals were invited to the study centres; for those who gave written informed consent a detailed questionnaire on demographics, socioeconomic status, asthma-related symptoms and comorbid conditions was administered. A trained technician performed spirometry. Individuals also reported their current employment status, their job title and a brief job description. In the present study, we restricted the cohort to adults in full-time employment.

\section{Variables}

Exposures

The two exposure variables in this study were the presence of PD and the level of asthma control. Based on the fact that we used a self-reported questionnaire, the term psychological distress (PD) was employed 
to broadly cover subclinical and clinical diagnosis. It refers to the presence of moderate to severe depressive and/or anxiety symptomatology rather than depression or anxiety as a clinical diagnosis.

\section{Psychological distress}

Depressive symptomatology. The Beck Depression Inventory II (BDI-II) [24] was used to measure the intensity of depressive symptoms. The BDI-II comprises 21 items rated on a behaviourally anchored answer scale ranging from 0 (absence of symptoms) to 3 (most severe symptoms) to assess symptom severity during the past week (including the current day). We used a cut-off score of 13 to diagnose the presence of clinically significant depressive symptomatology; this value has been established as the optimal cut-off point to in a sample of Canadian asthma patients [25].

Anxious symptomatology. The Beck Anxiety Inventory (BAI) [26] was used to measure the symptoms of anxiety. Respondents indicate the degree to which they have been bothered by each of the 21 symptom during the "past week including today" on a severity scale ranging from 0 ("not at all") to 3 ("severely, I could barely stand it"). A score of 16 has been determined as the optimal cut-off point to screen the presence of clinically significant anxiety symptomatology and was accordingly used in the present study [27].

The BDI-II and BAI are both validated instruments; additional analyses presented excellent psychometric properties in the current sample (see figures $s 1$ and s2 in the online supplementary material).

\section{Asthma control}

We applied the 2012 Global Initiative for Asthma (GINA) definition of asthma control [21]. In this definition, asthma is categorised into controlled, partially controlled, and uncontrolled based on measures of perceived impairment as well as the ratio of forced expiratory volume at $1 \mathrm{~s}$ (FEV1), obtained through spirometry, to its predicted value. We used the National Health and Nutrition Examination Survey (NHANES) III reference standards for calculating the predicted FEV1 [28].

\section{Outcomes}

Loss of work productivity

Using two validated instruments, the Work Productivity and Activity Impairment (WPAI) [29] and the Valuation of Lost Productivity (VOLP) [30] questionnaires, we quantified each individual's productivity loss in monetary values. The WPAI, validated in patients with asthma [29], measures the work time lost due to absenteeism and presenteeism, with a recall period of 1 week. The VOLP captures the contribution of the individual to team productivity, availability of a replacement and time sensitivity of the job [30, 31]. Combined with the wage rate, such information can be used to quantify the monetary value of productivity loss. The wage rate for each individual was estimated from sex- and age-specific hourly wages for the year 2010 by matching stated job titles and descriptions to National Occupation Classification codes $[32,33]$. All costs were in 2010 Canadian dollars (CAD\$).

\section{Statistical analyses}

We performed descriptive analysis of baseline variables according to asthma control levels and PD status. Unadjusted analysis included reporting on the weekly hours of lost work as well and the cost of productivity loss across levels of asthma control and PD.

We used two-part regression models to account for the fact that many individuals in our sample had zero productivity loss [34]. The first part of the two-part model was a logistic part estimating the probability of reporting productivity loss as a function of independent variables; the second part was an ordinary least squared (OLS) regression estimating the contribution of independent variables to the nominal value of productivity loss among those who reported loss of productivity. Two-part models are widely used in health economics studies to tackle zero-inflated data. A comprehensive review of cost-regression techniques has found two-part regression models to be generally perform better than simple models (e.g., Poisson regression) [34].

Both logistic and OLS parts of the model included an interaction term between asthma control level and PD status. A significant positive coefficient of the interaction term implies a synergistic effect (productivity loss in the presence of PD and uncontrolled asthma is more than the sum of productivity loss in individuals with either condition), whereas a negative one indicates an antagonistic effect. Confidence intervals and p-values were estimated using parametric bootstrapping by repeating the entire process 500 times. Such models were separately fitted for productivity loss due to absenteeism and presenteeism, and were adjusted for potentially confounding variables. Among a larger set of potentially relevant variables, the following covariates were included in the model based on exploratory analysis: sex, age, household income levels (low/high (>CAD\$60000 per year)), education (low/high (4-year college/university degree or higher)), type of residence (urban/rural), place of birth (Canada, yes/no), 
number of comorbid conditions (measured using the standardised comorbidity questionnaire, with variables indicating respiratory diseases and mental health disorders removed [35]), and, as a proxy for asthma severity, percentage of days covered by controller medication.

To determine whether there existed a particular at-risk phenotype for increased indirect cost burden, we ran separate models for each subtype of PD (depressive symptomatology alone, anxiety symptomatology alone, or combination of both).

All analyses were performed using Stata (version 12.1; StataCorp, College Station, TX, USA). Two-tailed p-values at 0.05 were considered statistically significant.

\section{Results}

\section{Study population characteristics}

Figure 1 illustrates the flowchart of the number of individuals according to their asthma control and PD status. The final sample consisted of 300 individuals. Table 1 presents their clinical and socio-demographic characteristics overall and across asthma control and PD status levels. The sample was $67 \%$ female and had a mean \pm SD age of $48 \pm 12$ years. These characteristics are in line with those of survey studies on asthmatics among workers in British Columbia [37]. However, the average income was higher (i.e., $62 \%$ of participants had a household income greater than the CAD\$60000, the median income in Canada) and, not surprising given the population-based sample, the majority of patients had mild asthma.

In 59 (20\%), $119(40 \%)$ and $122(40 \%)$ individuals, asthma was classified, respectively, as controlled, partially controlled and uncontrolled. PD was identified in 103 (34\%) patients, a value that is consistent with reported prevalence of PD in asthma $[15,38]$. The prevalence of PD monotonically increased as a function of asthma control: i.e., 24, 32 and $42 \%$ in patients with controlled, partially controlled and uncontrolled asthma, respectively $(\mathrm{p}=0.046)$. Regardless of the asthma control levels, patients suffering from PD were more likely to be female and have lower income compared with patients without PD (table 1). Patients with PD were also more likely to have a lower level of education.

\section{Unadjusted analysis}

Table 2 presents productivity loss estimates, without adjustment, overall and across asthma control levels stratified by PD status; in total, 146 (49\%) individuals reported productivity loss due to health conditions. Presenteeism was more common than absenteeism, with 137 (46\%) reporting presenteeism while 49 (16\%) reporting absenteeism. Regardless of the levels of asthma control, productivity loss was higher in individuals with PD, compared with those without PD (table 2). Similarly, regardless of PD, productivity

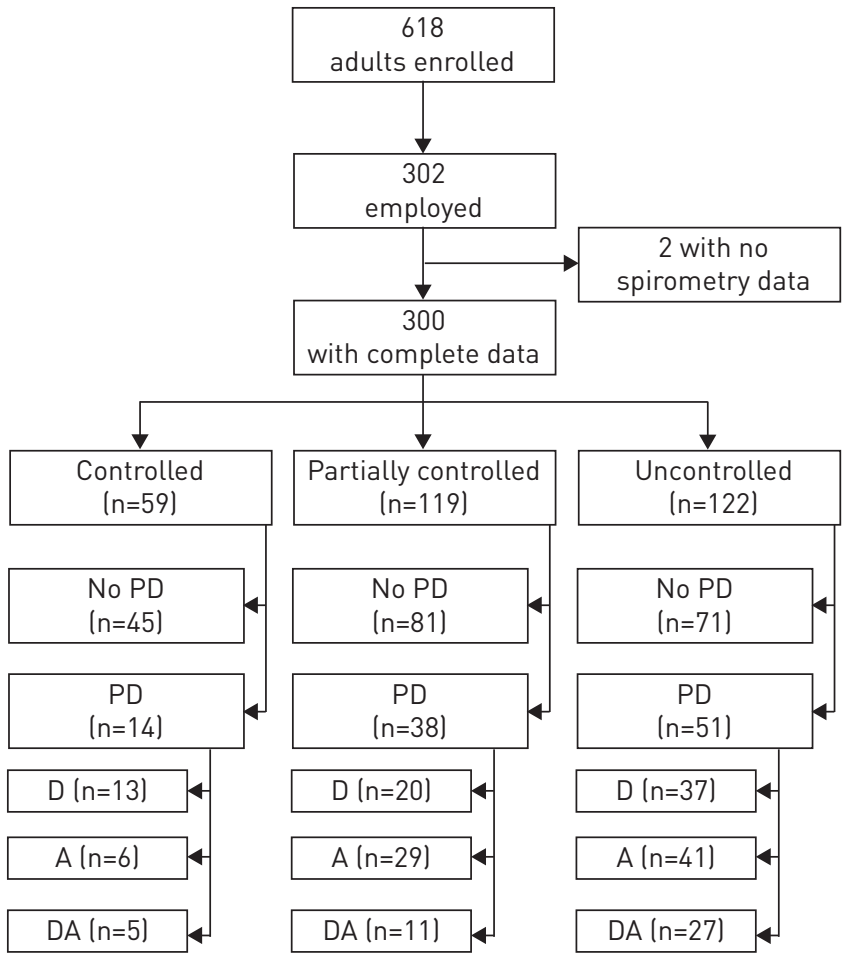

FIGURE 1 Flow chart of participants. PD: psychological distress (presence of clinically relevant anxious or depressive symptomatology); No PD: absence of psychological distress; D: presence of clinically relevant depressive symptomatology; A: presence of clinically relevant anxious symptomatology; DA: presence of both clinically relevant anxious and depressive symptomatology. 
TABLE 1 Demographic and clinical characteristics

\begin{tabular}{|c|c|c|c|c|c|c|c|c|c|c|}
\hline & \multirow[t]{2}{*}{ All subjects } & \multicolumn{3}{|c|}{$\begin{array}{c}\text { Controlled } \\
\text { asthma (n=59) }\end{array}$} & \multicolumn{3}{|c|}{$\begin{array}{l}\text { Partially controlled } \\
\text { asthma }(n=119)\end{array}$} & \multicolumn{3}{|c|}{$\begin{array}{l}\text { Uncontrolled } \\
\text { asthma ( } n=122)\end{array}$} \\
\hline & & PD & No PD & p-value $e^{\#}$ & PD & No PD & p-value ${ }^{\#}$ & PD & No PD & p-value \\
\hline Age & $48 \pm 12$ & $46 \pm 13$ & $46 \pm 13$ & 0.93 & $46 \pm 12$ & $49 \pm 12$ & 0.21 & $48 \pm 14$ & $49 \pm 10$ & 0.58 \\
\hline \multicolumn{11}{|l|}{ Sex } \\
\hline Women & 202 (67) & $11(79)$ & $30(67)$ & 0.52 & $30(79)$ & $42(52)$ & 0.005 & $41(80)$ & $48(68)$ & 0.15 \\
\hline High & $186(62)$ & $5(36)$ & $29(64)$ & 0.03 & $19(50)$ & 59 (73) & 0.03 & $26(51)$ & $51(72)$ & 0.007 \\
\hline Low & $103(34)$ & $9(64)$ & $12(27)$ & & $17(45)$ & $20(25)$ & & $23(45)$ & $19(27)$ & \\
\hline \multicolumn{11}{|l|}{ Education level $^{\S}$} \\
\hline High & $241(80)$ & $8(57)$ & $36(80)$ & 0.16 & $30(79)$ & $73(90)$ & 0.15 & $39(76)$ & $55(77)$ & 1.00 \\
\hline Low & $59(20)$ & $6(43)$ & $9(20)$ & & $8(21)$ & $8(10)$ & & $12(24)$ & $16(23)$ & \\
\hline \multicolumn{11}{|l|}{ Place of birth } \\
\hline Rural & $24(8)$ & $0(0)$ & $4(9)$ & & $4(11)$ & $5(6)$ & & $4(8)$ & $7(10)$ & \\
\hline \multicolumn{11}{|c|}{ Asthma medication adherence } \\
\hline $\mathrm{PDC}<50 \%$ & $182(61)$ & $12(86)$ & $37(82)$ & 1.00 & $34(89)$ & $56(69)$ & 0.014 & $18(35)$ & 25 (35) & 0.24 \\
\hline $50 \% \leqslant P D C<80 \%$ & $84(28)$ & $1(7)$ & $6(13)$ & & $2(5)$ & $21(26)$ & & $7(14)$ & $18(25)$ & \\
\hline $\mathrm{PDC} \geqslant 80 \%$ & $34(11)$ & 1 (7) & $2(4)$ & & $2(5)$ & $4(5)$ & & $26(51)$ & 28 (39) & \\
\hline Comorbidities & $2.2 \pm 2.6$ & $2.4 \pm 3.4$ & $1.8 \pm 2.0$ & 0.45 & $2.2 \pm 2.6$ & $1.8 \pm 2.1$ & 0.38 & $3.3 \pm 3.7$ & $1.9 \pm 2.3$ & 0.015 \\
\hline Range & $0-14$ & $0-11$ & $0-7$ & & $0-9$ & $0-8$ & & $0-14$ & $0-9$ & \\
\hline \multicolumn{11}{|l|}{ Asthma control level } \\
\hline Controlled & $59(20)$ & & & & & & & & & \\
\hline Partially controlled & $119(40)$ & & & & & & & & & \\
\hline Uncontrolled & $122(41)$ & & & & & & & & & \\
\hline \multicolumn{11}{|l|}{ Psychological distress } \\
\hline
\end{tabular}

Data are presented as $\mathrm{n}(\%)$ or mean $\pm \mathrm{SD}$, unless otherwise stated. PDC: percentage of days covered by asthma medication. ${ }^{\#}$ : psychological

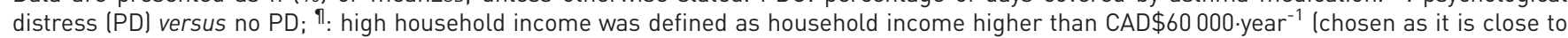
the median household income in Canada); ${ }^{+}$: a small number of patients $(11 / 300 ; 3 \%)$ had missing data on the covariate "household income levels", so, as per guidelines [36], we verified that these patients did not have specific characteristics and, thus, we performed a multiple imputation procedure and 20 imputed datasets were created; ${ }^{\S}$ : high education was defined as having obtained a 4-year college/university degree or higher; ${ }^{\dagger}$ : rural areas were defined as postal codes with $<400$ people $\cdot \mathrm{km}^{-2}$.

loss was higher in individuals with less controlled asthma. The work time lost ranged from $2 \mathrm{~h}$ per week (i.e., $5 \%$ of the worked time, assuming a weekly working time of $38 \mathrm{~h}$ ) in controlled asthma without PD, to $15 \mathrm{~h}$ (i.e., $44 \%$ of the worked time) in controlled asthma with PD.

\section{Adjusted analysis}

Table 3 shows the adjusted incremental burden due to productivity loss according to the different combinations of PD and asthma control levels. Compared with the reference group of patients with controlled asthma and with no PD, those with uncontrolled asthma and no PD had an additional CAD \$286 (95\%CI CAD \$276-297) weekly productivity loss, and those with controlled asthma but with PD had a CAD \$465 (95\%CI CAD\$445-485) productivity loss. Those with both uncontrolled asthma and PD had CAD $\$ 449$ (95\%CI CAD \$437-462) in productivity loss, which was not statistically different than the loss observed in individuals with controlled asthma and PD $(\mathrm{p}=0.98)$.

Figure 2 illustrates the adjusted productivity loss per week according to asthma control levels and PD conditions. The two-part regression models did not show significant interaction effect of PD with asthma control levels on productivity loss $(\beta=-5.88$ and $p=0.32$ for PD and partially controlled asthma; $\beta=-6.89$ and $\mathrm{p}=0.22$ for $\mathrm{PD}$ and uncontrolled asthma) (fig. 2). This was the case both for time loss due to presenteeism and absenteeism. 
TABLE 2 Productivity loss by psychological and by level of asthma control

\begin{tabular}{|c|c|c|c|c|c|c|c|c|c|c|}
\hline & \multirow[t]{2}{*}{ All subjects } & \multicolumn{3}{|c|}{$\begin{array}{c}\text { Controlled } \\
\text { asthma (n=59) }\end{array}$} & \multicolumn{3}{|c|}{$\begin{array}{l}\text { Partially controlled } \\
\text { asthma }(n=119)\end{array}$} & \multicolumn{3}{|c|}{$\begin{array}{l}\text { Uncontrolled } \\
(n=122)\end{array}$} \\
\hline & & PD & No PD & p-value & PD & No PD & p-value & PD & No PD & $\mathrm{p}$-value \\
\hline $\begin{array}{l}\text { Subjects n } \\
\text { Participants with } \\
\text { productivity loss }\end{array}$ & 300 & 14 & 45 & & 38 & 81 & & 51 & 71 & \\
\hline Any Type & 146 (49) & $10(71)$ & $12(27)$ & 0.004 & $25(66)$ & $28(35)$ & 0.002 & 37 (73) & $34(48)$ & 0.01 \\
\hline $\begin{array}{l}\text { Total hours worked } \\
\text { Hours lost }\end{array}$ & $36.1 \pm 17.8$ & $33.5 \pm 14.7$ & $38.0 \pm 15.4$ & 0.34 & $33.0 \pm 16.0$ & $35.9 \pm 17.0$ & 0.37 & $32.5 \pm 23.3$ & $39.9 \pm 16.6$ & 0.04 \\
\hline $\begin{array}{l}\text { Any Type } \\
\% \text { of time worked }\end{array}$ & $\begin{array}{c}7.6 \pm 14.3 \\
21\end{array}$ & $\begin{array}{c}14.9 \pm 18.3 \\
44\end{array}$ & $\begin{array}{c}2.0 \pm 6.3 \\
5\end{array}$ & $<0.001$ & $\begin{array}{c}10.1 \pm 17.7 \\
31\end{array}$ & $\begin{array}{c}4.3 \pm 10.0 \\
12\end{array}$ & 0.03 & $\begin{array}{c}13.4 \pm 18.1 \\
41\end{array}$ & $\begin{array}{c}7.8 \pm 14.1 \\
20\end{array}$ & 0.06 \\
\hline $\begin{array}{l}\text { Absenteeism } \\
\% \text { of time worked }\end{array}$ & $\begin{array}{c}2.1 \pm 7.0 \\
6\end{array}$ & $\begin{array}{c}6.3 \pm 10.7 \\
19\end{array}$ & $\begin{array}{c}1.2 \pm 6.1 \\
3\end{array}$ & 0.03 & $\begin{array}{c}3.0 \pm 10.9 \\
9\end{array}$ & $\begin{array}{c}0.7 \pm 2.5 \\
2\end{array}$ & 0.07 & $\begin{array}{c}3.8 \pm 8.9 \\
12\end{array}$ & $\begin{array}{c}1.7 \pm 5.7 \\
4\end{array}$ & 0.10 \\
\hline
\end{tabular}

Data are presented as $\mathrm{n}(\%)$ or mean \pm SD, unless otherwise stated. PD: comorbid psychological distress; No PD: no comorbid psychological distress. Bold indicates statistical significance.

\section{Subtypes of $P D$}

Depressive symptomatology had a major impact on productivity loss (due to both presenteeism and absenteeism) only in patients with controlled asthma. Conversely, regardless of asthma controls levels, anxiety symptomatology showed a comparable additive effect on productivity loss. Comorbid depressive and anxious symptomatology mainly affected presenteeism in subjects with uncontrolled asthma (detailed results are provided in figure $\mathrm{s} 2$ in the online supplementary material).

\section{Discussion}

The aim of this prospective population-based study was to examine the role of psychological distress (PD) and uncontrolled asthma on productivity loss. A previous study [13] by our team has shown achieving asthma control can be associated with significant gain in productivity. The present work goes further and demonstrates that the contribution of $\mathrm{PD}$, particularly from depressive symptomatology, to productivity loss dominates the impact of asthma control, such that in individuals with $\mathrm{PD}$, asthma control did not further affect productivity. Conversely, across all levels of asthma control, the presence of PD was associated with increased loss of productivity. Patients suffering from PD only (i.e. with controlled asthma) reported an adjusted incremental productivity loss estimated at $10.6 \mathrm{~h}$ of work-time loss per week and valued at $\mathrm{CAD} \$ 465$. Considering an average 50 weeks worked per year, it represents approximately CAD \$25000 per patient per year. Extrapolating these costs to on a population basis across Canada sends a strong message to policy makers on the additional burden of PD in asthma, especially considering that PD was prevalent in around one third of patients with asthma.

Previous studies [18-20] have focussed on the additional burden of comorbid PD in asthma compared with asthma alone. These papers showed that coexistence of PD with asthma is an important risk factor of additional costs for both asthma-related healthcare use and productivity loss, similar to the results reported in workers with cardio-vascular disease [39, 40] and diabetes [41, 42]. To our knowledge, our study is the first to have tested the combined effect of asthma control and PD on productivity loss, as two potentially modifiable conditions.

How can we explain that PD dominates uncontrolled asthma in terms of productivity loss? It may be related to the presence of a ceiling effect on productivity loss in patients with PD. Indeed, beyond a critical level of productivity loss (i.e. around half of the worked time), it is plausible that workers would be dismissed or be too sick to attend and miss time from work. In others words, the contribution of PD per se to the productivity loss may be large such that there is no room for synergy with effect of asthma control levels.

These results emphasise the importance for clinicians of taking a holistic view of asthma in its management [43]. After having prescribed maintenance therapy for controlling asthma, clinicians must remain vigilant about the potential presence of psychiatric co-morbidities, which, as our results indicate, greatly impact the 
TABLE 3 Results of the multivariate regression analysis of psychological distress status on productivity loss by asthma control levels

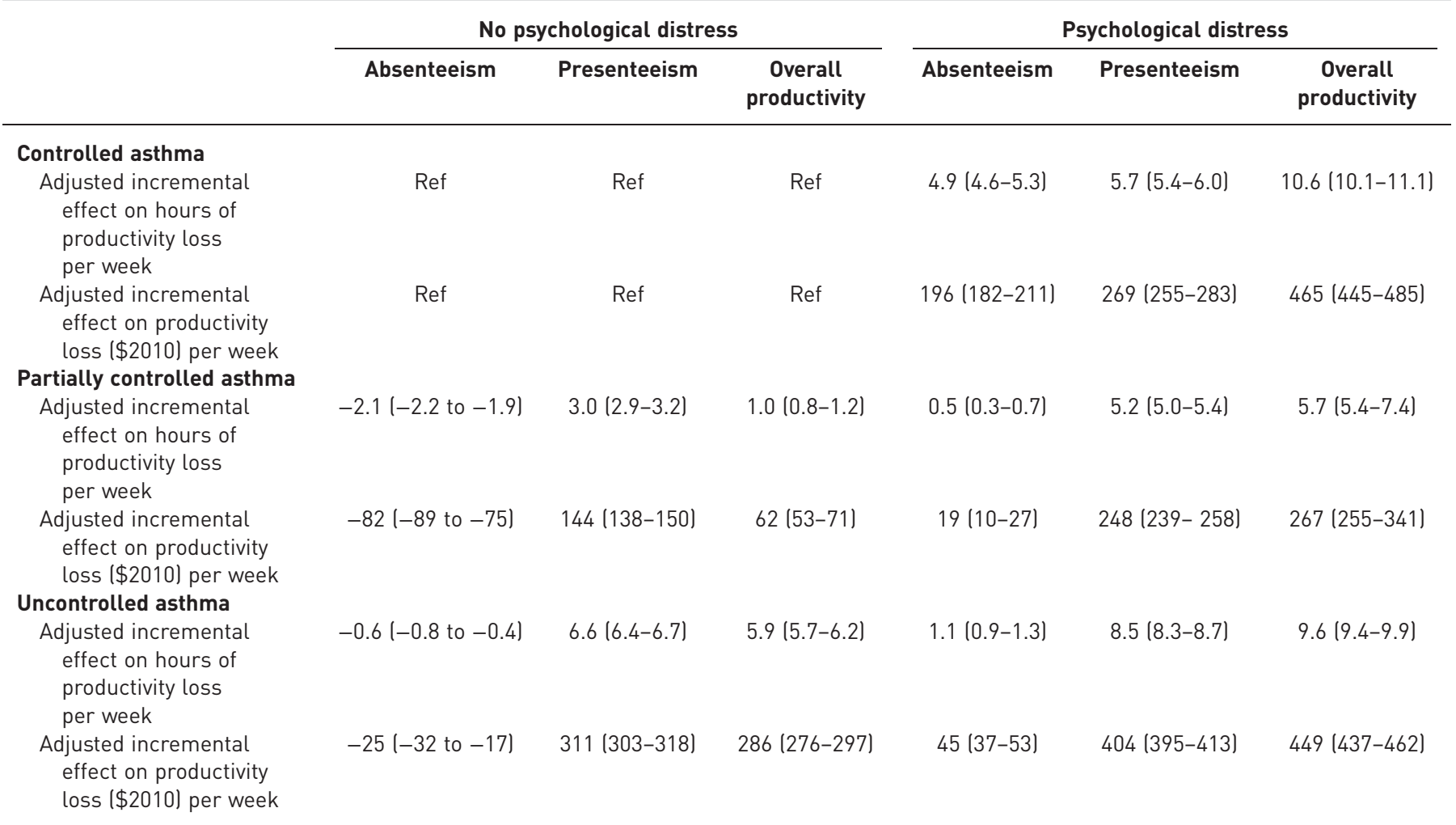

Data are presented as mean (95\% Cl). Values were adjusted for sex, age at baseline visit, household income, education, foreign born, type of residence (urban/rural), adherence to asthma medication and comorbidities.

burden of asthma. The purpose of this study was not to draw any causal inference between the occurrence of PD and uncontrolled asthma. However, previous research has shown that both uncontrolled asthma is a risk factor for developing PD [38] and PD is a risk factor for poor asthma control [44].
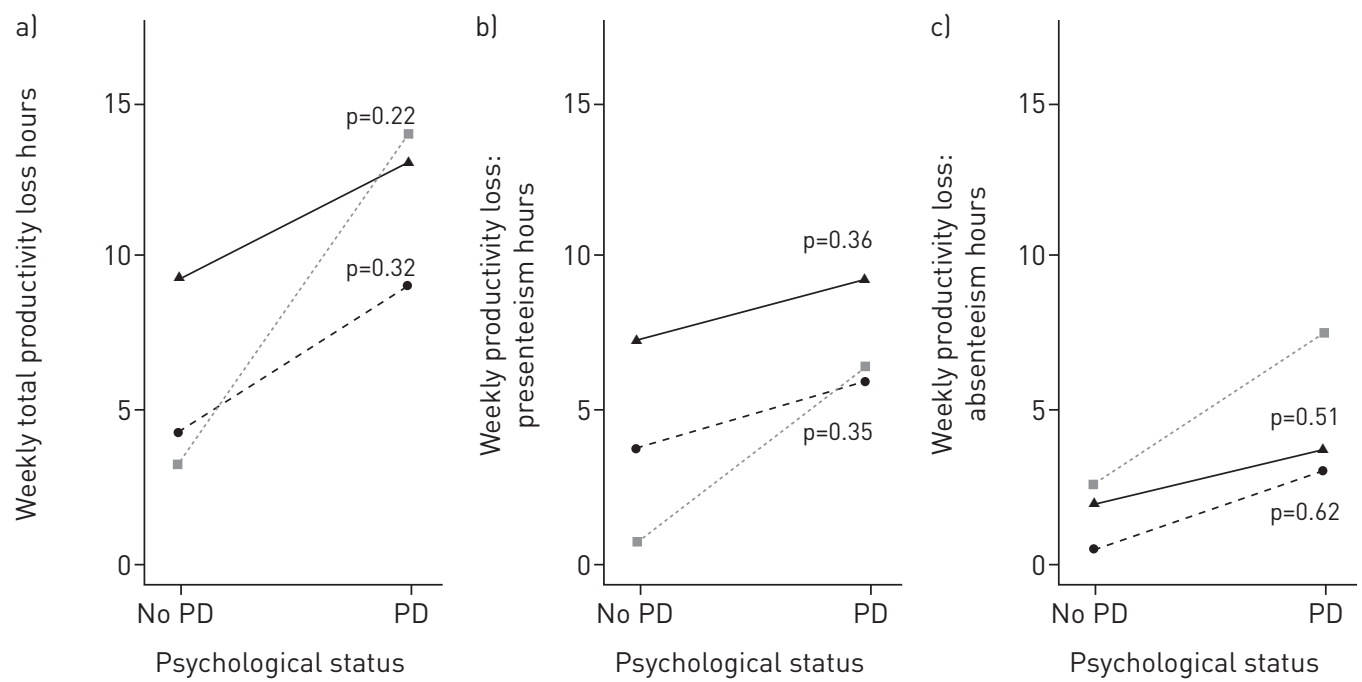

FIGURE 2 Interaction effect of psychological distress and asthma control levels on a) total productivity loss; b) productivity loss due to presenteeism; and c) productivity loss due to absenteeism. Dotted line and squares: controlled asthma; dashed line and circles: partially controlled asthma; solid line and triangles: uncontrolled asthma. PD: with comorbid psychological distress; No PD: no comorbid psychological distress. 
As a secondary objective of our study, we found that depressive symptomatology was associated with the largest productivity loss due to both presenteeism and absenteeism, compared with anxiety symptomatology. These results are consistent with those of the large Dutch population-based study by Buist-Bouwman et al. [19], which found that mood disorders, followed by anxiety disorders, were the mental disorders the most associated with work-loss days. These results are also consistent with the recent findings from the last edition of the Global Burden Disease study [45] demonstrating that among mental disorders, depression disorders were worldwide the largest contributor to the burden of mental health conditions (40\%); particularly in terms of years lived with disability, followed by anxiety disorders (14.5\%).

Our study has some limitations that warrant caution in the interpretation of findings. First, none of the participants reported being unemployed because of asthma; it was thus not possible to capture the potential contribution of this aspect of the burden of asthma. Second, using a cross-sectional design, we were not able to evaluate the temporal sequence between PD and productivity loss. As such, we cannot rule out the possibility that, in some individuals, it is productivity loss (e.g., due to uncontrolled asthma) that causes PD. Even in this case it is likely that the addition of PD further reduces the individual's job performance, indicating that treatment for PD will still be associated with gain in productivity. Third, even with 300 participants, our study might have been underpowered to make inference on costs which often have large variability. Fourth, our estimates did not include indirect costs for employers involved in greater supervision when workers experienced PD symptoms, due to increased work pressure, or work intensification. Next, although the BDI-II and BAI are two widely used tools in asthma literature, the use of self-administered questionnaires is not ideal compared with structured psychiatric interviews to identify the presence of clinical disorders. However, the cut-off score used in the present study for BDI-II (i.e. 13) was specifically determined on a sample of Canadian asthma patients, thereby reducing the risk of misclassification diagnosis. Finally, considering that productivity loss was self-reported, patients suffering from PD, known to have distorted and pessimistic perceptions, may have over-estimated their work loss, causing a spurious positive effect.

\section{Conclusions}

Notwithstanding the potential limitations of the study, our results confirm that uncontrolled asthma and PD are two modifiable conditions associated with substantial indirect costs in workers with asthma. The effect of PD on productivity seems to be such that in its presence, the further additive effect of asthma control on productivity loss is minimal. Considering the rising prevalence of asthma worldwide in the last decades, policy-makers should be aware of the risk of added burden for this portion of asthma patients suffering from PD. It is likely that studies in other chronic conditions also document the devastating effect of comorbid PD on productivity loss, over and beyond the effect of the disease itself [39-42]. It appears urgent that agencies and governments give mental health the due priority and optimise the existing resources to prevent this comorbidity. Further research is needed to evaluate the cost-effectiveness of interventions designed to modify the psychological morbidity in patients with asthma.

\section{Acknowledgements}

The EBA study team were Aydn Bekirov, Satvir Dhoot, Lisa Dinh, Jennie Chan, Jesmin Dhillon, Gurleen Gill, Jessika Iwanski, Zaakir Jiwa, Intan Agoes, Richie Li, Jordan Deppiesse, Samantha Gray, Elena Terekhova, Nicole Brunton, Dayna Taylor, Madeline Ludwig, Laura FitzGerald, Meicun Zou, Elisabeth McClymont, Douglass Rolfe and Wan Tan Hogg (all Institute for Heart and Lung Health, Department of Medicine, University of British Columbia, Vancouver, BC, Canada).

\section{References}

1 Peters SP, Jones CA, Haselkorn T, et al. Real-world Evaluation of Asthma Control and Treatment (REACT): findings from a national Web-based survey. J Allergy Clin Immunol 2007; 119: 1454-1461.

2 Chapman KR, Boulet LP, Rea RM, et al. Suboptimal asthma control: prevalence, detection and consequences in general practice. Eur Respir J 2008; 31: 320-325.

3 Demoly P, Paggiaro P, Plaza V, et al. Prevalence of asthma control among adults in France, Germany, Italy, Spain and the UK. Eur Respir Rev 2009; 18: 105-112.

4 Vollmer WM, Markson LE, O'Connor E, et al. Association of asthma control with health care utilization: a prospective evaluation. Am J Respir Crit Care Med 2002; 165: 195-199.

5 Williams SA, Wagner S, Kannan $\mathrm{H}$, et al. The association between asthma control and health care utilization, work productivity loss and health-related quality of life. J Occup Environ Med 2009; 51: 780-785.

6 Carlton BG, Lucas DO, Ellis EF, et al. The status of asthma control and asthma prescribing practices in the United States: results of a large prospective asthma control survey of primary care practices. J Asthma 2005; 42: 529-535.

7 Bateman ED, Reddel HK, Eriksson G, et al. Overall asthma control: the relationship between current control and future risk. J Allergy Clin Immunol 2010; 125: 600-608.

8 Cisternas MG, Blanc PD, Yen IH, et al. A comprehensive study of the direct and indirect costs of adult asthma. J Allergy Clin Immunol 2003; 111: 1212-1218.

9 Colice G, Wu EQ, Birnbaum H, et al. Healthcare and workloss costs associated with patients with persistent asthma in a privately insured population. J Occup Environ Med 2006; 48: 794-802.

10 Smith DH, Malone DC, Lawson KA, et al. A national estimate of the economic costs of asthma. Am J Respir Crit Care Med 1997; 156: 787-793. 
11 Bahadori K, Doyle-Waters MM, Marra C, et al. Economic burden of asthma: a systematic review. BMC Pulm Med 2009; 9: 24.

12 Ernst R. Indirect costs and cost-effectiveness analysis. Value Health 2006; 9: 253-261.

13 Sadatsafavi M, Rousseau R, Chen W, et al. The preventable burden of productivity loss due to suboptimal asthma control: a population-based study. Chest 2014; 145: 787-793.

14 Weiss KB, Gergen PJ, Hodgson TA. An economic evaluation of asthma in the United States. N Engl J Med 1992; 326: $862-866$.

15 Goodwin RD, Jacobi F, Thefeld W. Mental disorders and asthma in the community. Arch Gen Psychiatry 2003; 60: $1125-1130$.

16 Simon G, Ormel J, VonKorff M, et al. Health care costs associated with depressive and anxiety disorders in primary care. Am J Psychiatry 1995; 152: 352-357.

17 Kessler RC, Akiskal HS, Ames M, et al. Prevalence and effects of mood disorders on work performance in a nationally representative sample of U.S. workers. Am J Psychiatry 2006; 163: 1561-1568.

18 Holden L, Scuffham PA, Hilton MF, et al. Health-related productivity losses increase when the health condition is co-morbid with psychological distress: findings from a large cross-sectional sample of working Australians. BMC Public Health 2011; 11: 417.

19 Buist-Bouwman MA, de Graaf R, Vollebergh WA, et al. Comorbidity of physical and mental disorders and the effect on work-loss days. Acta Psychiatr Scand 2005; 111: 436-443.

20 Baune BT, Adrian I, Jacobi F. Medical disorders affect health outcome and general functioning depending on comorbid major depression in the general population. J Psychosom Res 2007; 62: 109-118.

21 Global Initiative for Asthma (GINA). Global Strategy for Asthma Management and Prevention 2014. Available from www.ginasthma.org/local/uploads/files/GINA_Report_2014_Aug12.pdf Date last updated: Aug 12, 2014; Date last accessed: Dec 17, 2014.

22 Chen W, Fitzgerald JM, Rousseau R, et al. Complementary and alternative asthma treatments and their association with asthma control: a population-based study. BMJ Open 2013; 3: e003360.

23 Statistics Canada. Open Data for 2011 Census, British Columbia, Canada. Available from www.bcstats.gov.bc.ca/ StatisticsBySubject/Census/OpenData.aspx Date last accessed: Dec 17, 2014.

24 Beck AT, Steer RA, Brown GK. Manual of the Beck Depression Inventory. 2nd Edn. San Antonio, The Psychological Corporation, 1996.

25 Moullec G, Plourde A, Bacon S, et al. Screening properties of Beck Depression Inventory-II in patients with asthma. Psychosom Med 2012; 74: A55.

26 Beck AT, Epstein N, Brown G, et al. An inventory for measuring clinical anxiety: psychometric properties. J Consult Clin Psychol 1988; 56: 893-897.

27 Beck AT, Steer RA. Beck Anxiety Inventory Manual. San Antonio, The Psychological Corporation Harcourt Brace and Company, 1993.

28 Hankinson JL, Odencrantz JR, Fedan KB. Spirometric reference values from a sample of the general U.S. population. Am J Respir Crit Care Med 1999; 159: 179-187.

29 Andreasson W, Svensson K, Bergreen F. The validity of the work productivity and activity impairment questionnaire for patients with asthma (WPAI-Asthma): Results from a web-based study. Value Health 2003; 6: 780.

30 Zhang W, Bansback N, Boonen A, et al. Development of a composite questionnaire, the valuation of lost productivity, to value productivity losses: application in rheumatoid arthritis. Value Health 2012; 15: 46-54.

31 Pauly MV, Nicholson S, Polsky D, et al. Valuing reductions in on-the-job illness: "presenteeism" from managerial and economic perspectives. Health Econ 2008; 17: 469-485.

32 Employment and Social Development Canada. National Occupational Classification 2006. Date last updated: Oct 29, 2013; Date last accessed: Dec 17, 2014.

33 CANSIM - 282-0070. Labour force survey estimates (LFS), wages of employees by type of work, National Occupational Classification for Statistics (NOC-S), sex and age group. Available from www5.statcan.gc.ca/cansim/ Date last updated: Nov 14, 2014. Date last accessed: Dec 17, 2014.

34 Mihaylova B, Briggs A, O'Hagan A, et al. Review of statistical methods for analysing healthcare resources and costs. Health Econ 2011; 20: 897-916.

35 Sangha O, Stucki G, Liang MH, et al. The Self-Administered Comorbidity Questionnaire: a new method to assess comorbidity for clinical and health services research. Arthritis Rheum 2003; 49: 156-163.

36 Sterne JA, White JR, Carlin JB, et al. Multiple imputation for missing data in epidemiological and clinical research: potential and pitfalls. BMJ 2009; 338: b2393.

37 Koehoorn M, Tamburic L, McLeod CB, et al. Population-based surveillance of asthma among workers in British Columbia, Canada. Chronic Dis Inj Can 2013; 33: 88-94.

38 Lavoie KL, Bacon SL, Barone S, et al. What is worse for asthma control and quality of life: depressive disorders, anxiety disorders, or both? Chest 2006; 130: 1039-1047.

39 Kessler R, White LA, Birnbaum H, et al. Comparative and interactive effects of depression relative to other health problems on work performance in the workforce of a large employer. J Occup Environ Med 2008; 50: 809-816.

40 Stein MB, Cox BJ, Afifi TO, et al. Does co-morbid depressive illness magnify the impact of chronic physical illness? A population-based perspective. Psychol Med 2006; 36: 587-596.

41 Druss BG, Rosenheck RA, Sledge WH. Health and disability costs of depressive illness in a major U.S. corporation. Am J Psychiatry 2000; 157: 1274-1278.

42 Kivimaki M, Vahtera J, Pentti J, et al. Increased sickness absence in diabetic employees: what is the role of co-morbid conditions? Diabet Med 2007; 24: 1043-1048.

43 FitzGerald JM, Poureslami I. The need for humanomics in the era of genomics and the challenge of chronic disease management. Chest 2014; 146: 10-12.

44 Favreau H, Bacon SL, Labrecque M, et al. Prospective impact of panic disorder and panic-anxiety on asthma control, health service use, and quality of life in adult patients with asthma over a 4-year follow-up. Psychosom Med 2014; 76: 147-155.

45 Whiteford HA, Degenhardt L, Rehm J, et al. Global burden of disease attributable to mental and substance use disorders: findings from the Global Burden of Disease Study 2010. Lancet 2013; 382: 1575-1586. 